\title{
LOGÍSTICA DE MOVIMENTAÇÃO E ANÁLISE DAS PERDAS TÉRMICAS DA PANELA DE GUSA DA VSB*
}

\author{
Marcos Figueiredo Nicolau ${ }^{1}$ \\ Ronaldo Santos Sampaio 2 \\ Paulo César Lemes de Almeida ${ }^{3}$ \\ Aline Miranda Pessoa Passagli ${ }^{4}$ \\ Thiago André Oliveira ${ }^{5}$
}

\section{Resumo}

O fluxo de produção da VSB contempla um alto-forno a carvão vegetal e uma aciaria elétrica. Para melhor sincronizar a programação do alto-forno (AF) e a do forno elétrico (FEA) é importante ter um conhecimento prévio de quais corridas do FEA usarão gusa líquido. Foi desenvolvido este projeto visando auxiliar na tomada de decisões da programação do AF e do FEA, a partir de uma simulação da logística de movimentação das panelas de gusa em cenários pré-determinados. Dentre as respostas que podem ser obtidas por essa contribuição técnica destacam-se: o número mínimo de panelas que devem ser utilizadas no circuito, quantas e quais corridas do forno elétrico serão atendidas com gusa líquido e a contribuição de cada meio de transferência de calor para a perda térmica total.

Palavras-chave: Alto-forno; Panela; Forno elétrico; Logística.

\section{TRANSPORT LOGISTICS AND THERMAL LOSSES ANALYSES IN VSB HOT METAL LADLE}

\begin{abstract}
VSB production flow comprises a charcoal blast furnace and an electric steel plant. In order to have a better synchronization of their schedules, it is important to have a prior knowledge of what heats of the Electric Arc Furnace will use hot metal. This project has been developed to help the Blast and Electric Arc Furnaces scheduling decisions, from a simulation of the hot metal ladle movement logistics in predetermined scenarios. Among the answers that can be obtained by this project we highlight the minimum number of ladles to be used in the circuit, how many and which Electric Arc Furnace heats will be met with hot metal and a transient energy balance to evaluate the contribution of each heat transfer way to the total thermal loss.
\end{abstract}

Keywords: Blast furnace; Ladle; Electric arc furnace; Logistics.

1 Bacharel em Engenharia Química, Universidade Federal de Minas Gerais, Belo Horizonte, Minas Gerais, Brasil.

2 Engenheiro Metalurgista, Mestre e Doutor em Metalurgia e Ciência dos Materiais, Diretor, RSConsultants, Belo Horizonte, Minas Gerais, Brasil.

3 Engenheiro Metalurgista, engenheiro de processo do alto-forno, gerência de alto-forno, Vallourec \& Sumitomo Tubos do Brasil, Jeceaba, Minas Gerais, Brasil.

4 Engenheira de Produção, coordenadora da equipe de controle de processo, gerência de altoforno, Vallourec \& Sumitomo Tubos do Brasil, Jeceaba, Minas Gerais, Brasil.

5 Engenheiro Químico, engenheiro de processo da metalurgia primária e secundária, gerência de aciaria, Vallourec \& Sumitomo Tubos do Brasil, Jeceaba, Minas Gerais, Brasil.

\footnotetext{
* Contribuição técnica ao $44^{\circ}$ Seminário de Redução de Minério de Ferro e Matérias-primas, 15ํ Simpósio Brasileiro de Minério de Ferro e $2^{\circ}$ Simpósio Brasileiro de Aglomeração de Minério de Ferro, 15 a 18 de setembro de 2014, Belo Horizonte, MG, Brasil.
} 


\section{INTRODUÇÃO}

No fluxo de produção da Vallourec \& Sumitomo Tubos do Brasil, VSB, está contemplado um alto-forno a carvão vegetal e uma aciaria elétrica. Para melhor sincronizar a situação atual de programação do alto-forno (AF) com a do forno elétrico (FEA) é importante ter um conhecimento prévio de quais corridas do FEA usarão ferro gusa líquido produzido do AF. Esta contribuição técnica foi desenvolvida visando auxiliar a tomada de decisões da programação do AF e do FEA, a partir de uma simulação da logística de movimentação das panelas de gusa em cenários pré-determinados, a fim de:

- otimizar o número de corridas do FEA que usarão gusa proveniente do AF;

- diminuir as perdas térmicas por espera e evitar, sempre que possível, que as panelas sejam destinadas à maquina de lingotar gusa.

O objetivo do presente trabalho é avaliar dois cenários padrões no funcionamento da planta de produção, o primeiro com o alto-forno operando com uma produtividade de $1,6 \mathrm{t} / \mathrm{dia} / \mathrm{m}^{3}$ e o segundo operando com $2,4 \mathrm{t} / \mathrm{dia} / \mathrm{m}^{3}$, em um dia de operação convencional do alto-forno e do forno elétrico. As principais respostas que se visa obter são:

- número mínimo de panelas utilizadas no circuito;

- destino de cada panela, com base na logística de movimentação e análise de perdas térmicas;

- quantas e quais corridas do FEA foram atendidas com gusa-líquido;

- Intervalo de tempo disponível para aquecimento ou pequenas intervenções nas panelas ou na lingotadeira;

- o percentual de tempo que as panelas estariam cheias de gusa-líquido.

Paralelamente ao estudo da logística de movimentação das panelas, foi desenvolvido um balanço de energia transiente para a panela aberta, sem o uso de nenhuma cobertura, e uma panela tampada. Esse balanço gera como respostas um gráfico comparativo da temperatura do gusa líquido dentro da panela versus o tempo e um gráfico que avalia a contribuição de cada meio de transferência de calor para a taxa de perda térmica total do gusa líquido.

\section{MATERIAIS E MÉTODOS}

\subsection{Modelo de Logística de Movimentação}

O modelo de logística de movimentação das panelas de gusa líquido é composto por um arquivo em Microsoft Excel e um arquivo em um software específico de simulação. A Figura 1 ilustra simplificadamente o sistema que é contemplado nas simulações de cenários, que corresponde ao sistema do processo produtivo da VSB.

\footnotetext{
* Contribuição técnica ao $44^{\circ}$ Seminário de Redução de Minério de Ferro e Matérias-primas, 15ํ Simpósio Brasileiro de Minério de Ferro e $2^{\circ}$ Simpósio Brasileiro de Aglomeração de Minério de Ferro, 15 a 18 de setembro de 2014, Belo Horizonte, MG, Brasil.
} 


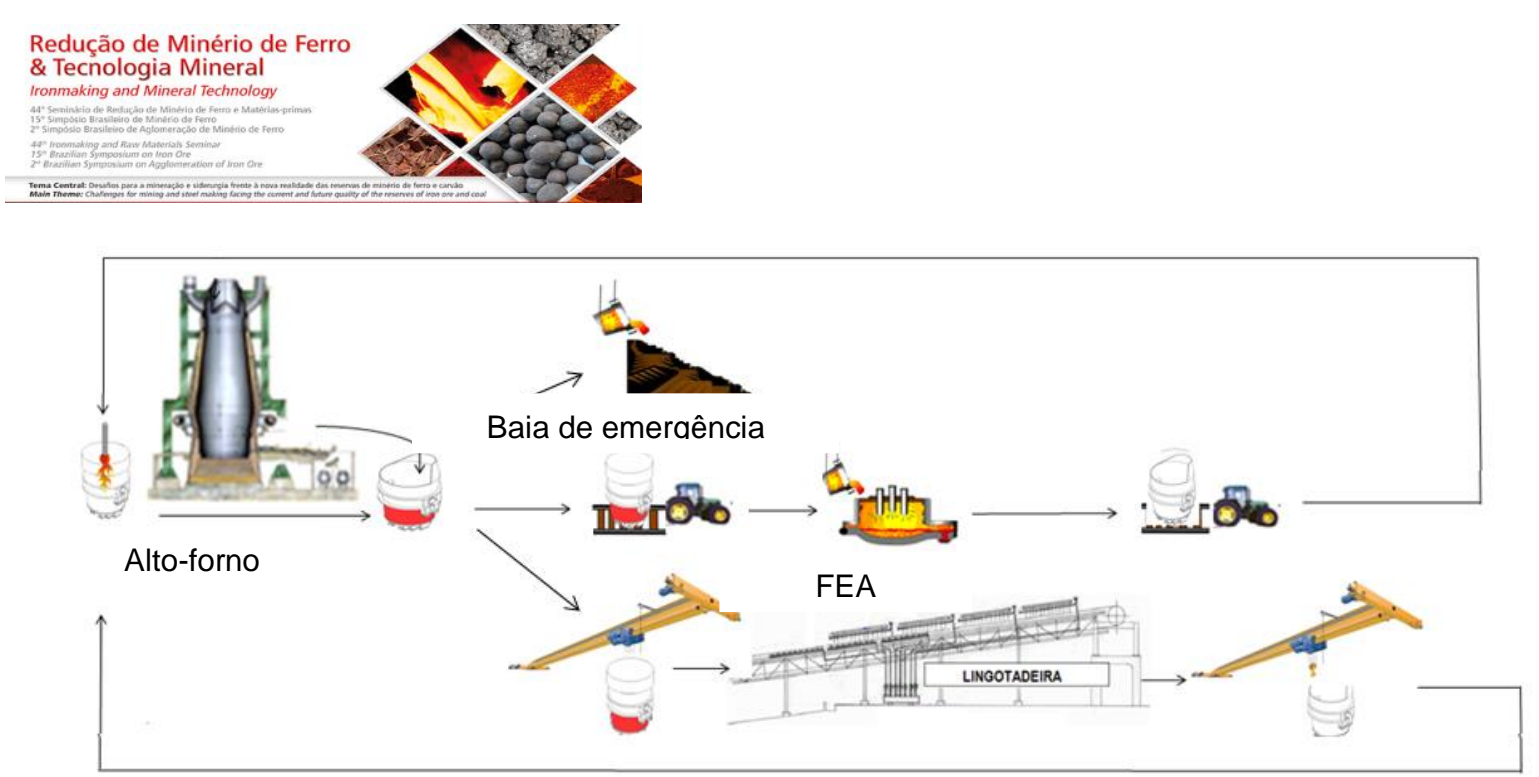

Figura 1. Sistema simulado pelo modelo de logística.

As panelas, que são as entidades da simulação, recebem o gusa líquido na bica do alto-forno e, dependendo da logística de transporte, da programação do forno elétrico e das análises da perdas térmicas, são enviadas ou para o FEA, ou para a máquina de lingotar gusa, ou, em uma situação mais extrema, para a baia de emergência, na qual o gusa é despejado na baia de emergência, a fim de se evitar que ele se solidifique dentro da panela. Após passarem por alguma dessas etapas, as panelas são novamente direcionadas ao alto-forno para serem utilizadas novamente no processo.

Os dados de entrada necessários para as simulações são todos preenchidos na tabela Excel. Quando o usuário executa a simulação no software específico, estes dados são automaticamente importados pelo software, a simulação de todo o tempo programado é feita e, também automaticamente, as respostas são exportadas para o mesmo arquivo Excel. Os principais dados de entrada para a simulação dos dois cenários incluídos nesse relatório estão apresentados na Tabela 1.

Tabela 1. Principais dados de entrada para as simulações.

\begin{tabular}{c|c|c}
\hline Variável de Entrada & \multicolumn{2}{|c}{$\begin{array}{c}\text { Operação Convencional do Alto- } \\
\text { Forno e do Forno Elétrico }\end{array}$} \\
\hline $\begin{array}{c}\text { Produtividade AF } \\
\left.\text { (t/dia/m }{ }^{3}\right)\end{array}$ & 1,6 & 2,4 \\
\hline $\begin{array}{c}\text { Número de Panelas no } \\
\text { Circuito }\end{array}$ & 2 & 2 \\
\hline $\begin{array}{c}\text { Tempo de Alto-Forno } \\
\text { aberto/fechado }\end{array}$ & $3: 00 / 1: 00$ & $3: 10 / 0: 50$ \\
\hline $\begin{array}{c}\text { Número de corridas } \\
\text { por dia }\end{array}$ & 6 & 6 \\
\hline $\begin{array}{c}\text { Produção por corrida } \\
\text { (t) }\end{array}$ & 93 & 140 \\
\hline $\begin{array}{c}\text { Número de panelas } \\
\text { vazadas por corrida do } \\
\text { AF }\end{array}$ & 1 & 24 \\
\hline $\begin{array}{c}\text { Programação do Forno } \\
\text { Elétrico }\end{array}$ & Sequência de & Sequência de \\
\hline
\end{tabular}

* Contribuição técnica ao 44ํㅗㄴ Seminário de Redução de Minério de Ferro e Matérias-primas, 15o Simpósio Brasileiro de Minério de Ferro e 2o Simpósio Brasileiro de Aglomeração de Minério de Ferro, 15 a 18 de setembro de 2014, Belo Horizonte, MG, Brasil. 
Além dos dados tabelados anteriormente, alguns dados como os tempos gastos em cada processo, o tempo gasto em cada transporte, a temperatura do gusa no canal do alto-forno, a temperatura mínima do gusa aceita pelo FEA e as perdas térmicas de cada etapa também devem ser preenchidos na planilha Excel.

As respostas das simulações são obtidas na forma de um Gráfico de Gantt, no qual as colunas representam o tempo de toda a simulação programada e as linhas representam todas as possíveis posições que as panelas podem apresentar durante todo o circuito. Um exemplo de um gráfico obtido por uma simulação está apresentado na Figura 2.

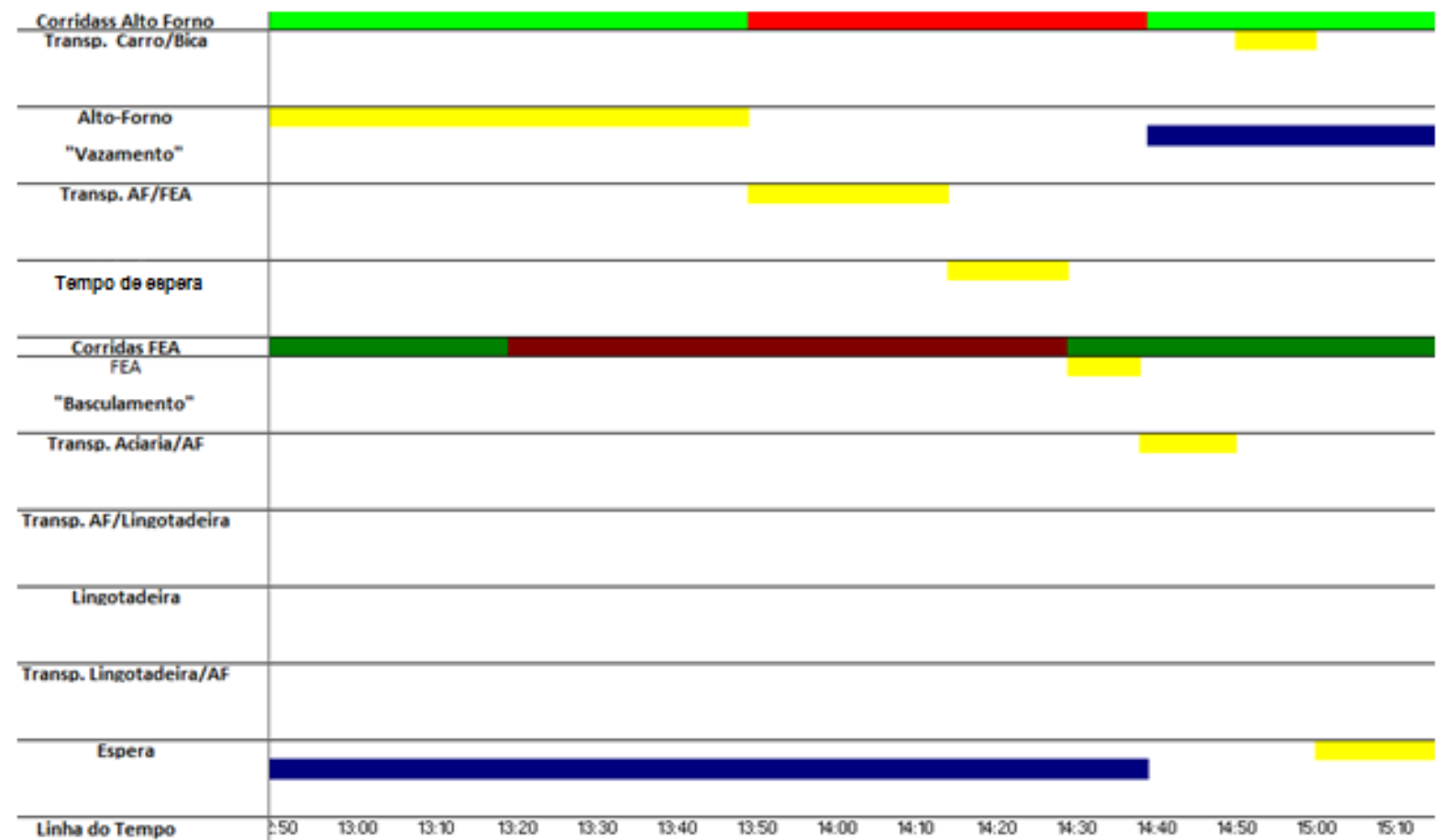

Figura 2. Gráfico de Gantt obtido como resposta da simulação.

$\mathrm{Na}$ Figura 2 pode ser visto que a primeira linha do gráfico mostra quando o alto-forno está aberto, em verde, e fechado, em vermelho, a linha denominada "Corridas FEA" mostra a duração de cada corrida subsequente e as demais linhas mostram as posições das panelas, como por exemplo, recebendo gusa no alto-forno, sendo transportada do AF para o FEA ou simplesmente esperando para ser utilizada em outra etapa do processo. Nota-se também, que cada panela é representada por uma diferente cor (neste exemplo, amarelo e azul). A linha referente ao tempo de espera indica o tempo que a panela está disponível no basculador do FEA antes de iniciar a corrida.

Juntamente ao gráfico, são obtidos também alguns importantes indicadores, que resultam da análise dos dados gerados pelas simulações. Estes indicadores são mostrados na Figura 3.

* Contribuição técnica ao 44 Seminário de Redução de Minério de Ferro e Matérias-primas, 15ㅇ Simpósio Brasileiro de Minério de Ferro e 2o Simpósio Brasileiro de Aglomeração de Minério de Ferro, 15 a 18 de setembro de 2014, Belo Horizonte, MG, Brasil. 


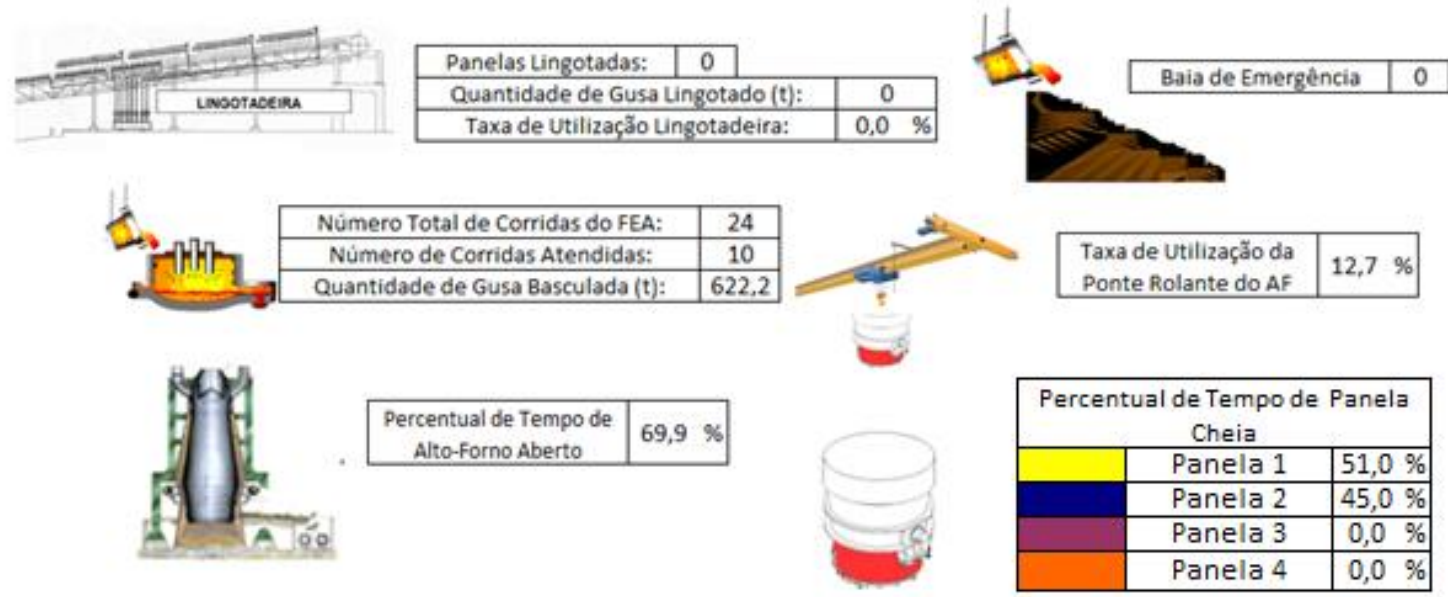

Figura 3. Indicadores obtidos na simulação.

Dentre estes indicadores, destacam-se o número total de corridas do FEA, o número de corridas atendidas com gusa líquido proveniente do $\mathrm{AF}$, a taxa de utilização da ponte rolante do alto-forno e o percentual de tempo que cada panela permanece cheia durante toda a simulação.

\subsection{Análise das Perdas Térmicas}

Para a análise das perdas térmicas, foram feitos dois balanços de energia transientes, um para a panela sem tampa e com a superfície de gusa sem cobertura e outro para a panela tampada, considerando, para cada um deles, os principais meios de transferência de calor. A Figura 4 a seguir mostra os meios de transferência de calor considerados para o balanço da panela sem a tampa.

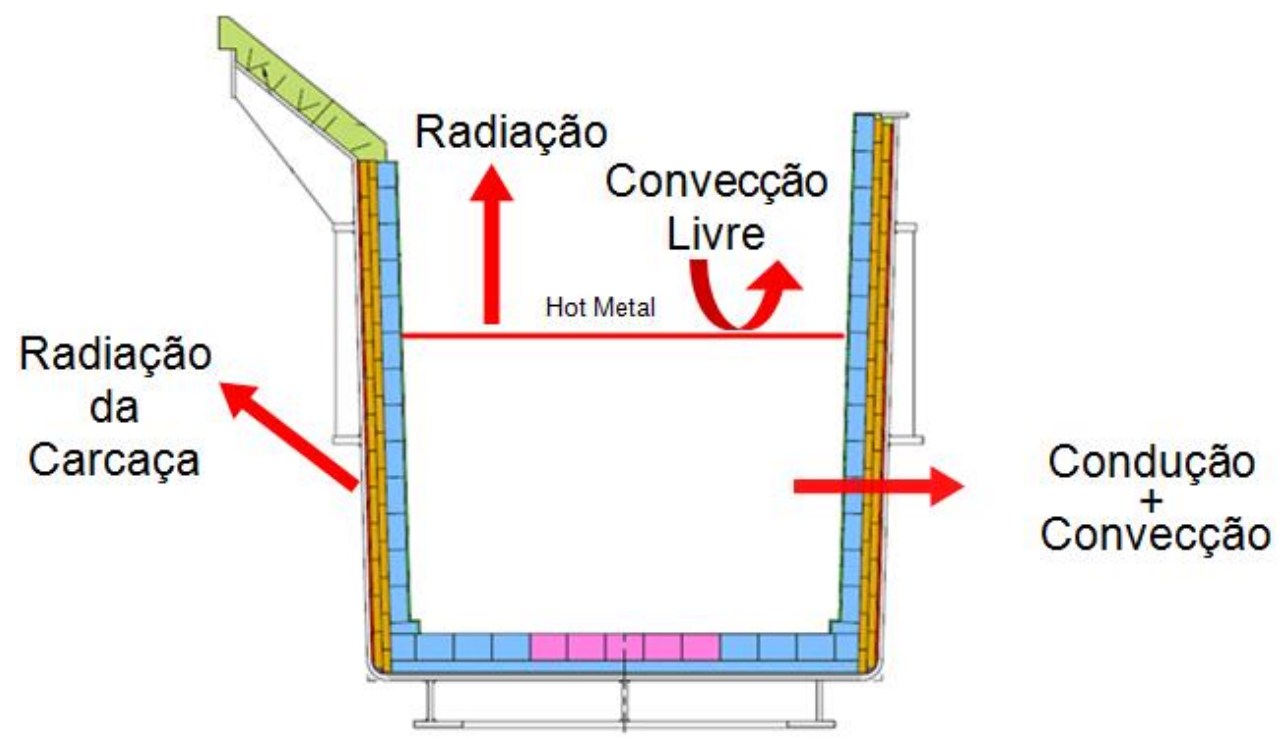

Figura 4. Meios de transferência de calor considerados no balanço de energia.

A Equação 1 é a equação obtida para o balanço da panela destampada é:

$t=\int_{T i}^{T f} \frac{\rho * V * C p}{U_{L} * A_{L} *\left(T_{\infty}-T\right)+\varepsilon_{A c ̧ o} * \sigma * A_{L} *\left(T_{\infty}^{4}-T_{E x t}^{4}\right)+h * A_{\text {Sup }} *\left(T_{\infty}-T\right)+\varepsilon_{\text {Gusa }} * \sigma * A_{\text {Sup }} *\left(T_{\infty}^{4}-T^{4}\right)} d T$

* Contribuição técnica ao 44 Seminário de Redução de Minério de Ferro e Matérias-primas, 15ํ Simpósio Brasileiro de Minério de Ferro e $2^{\circ}$ Simpósio Brasileiro de Aglomeração de Minério de Ferro, 15 a 18 de setembro de 2014, Belo Horizonte, MG, Brasil. 
Em que $\rho, V$ e Cp são a densidade, o volume e o calor específico, respectivamente, do gusa dentro da panela. UL e AL são o coeficiente global de transferência de calor e a área da parede lateral da panela de gusa. $T_{\infty}$ é a temperatura ambiente, $\mathrm{T}$ a temperatura do gusa, $\boldsymbol{\varepsilon}_{\text {Aço }}$ a emissividade do aço, utilizada para o cálculo da radiação da carcaça da panela, $\boldsymbol{\sigma}$ a constante de Stefan-Boltzmann, TEXT a temperatura da parede externa da panela, h o coeficiente de convecção livre do ar na superfície do gusa, Asup a área da superfície de gusa e $\varepsilon_{\text {Gusa }}$ a emissividade da superfície do gusa líquido.

A Equação 2 é a equação obtida para o balanço de energia da panela com tampa:

$$
t=\int_{T i}^{T f} \frac{\rho * V * C p}{U_{L} * A_{L} *\left(T_{\infty}-T\right)+\varepsilon_{A c ̧ o} * \sigma * A_{L} *\left(T_{\infty}^{4}-T_{E x t}^{4}\right)+U_{T a m p a} * A_{T a m p a} *\left(T_{\infty}-T\right)} d T
$$

Onde UTampa é coeficiente global de transferência de calor na tampa da panela e ATampa a área externa da tampa da panela.

A integração numérica dessas duas equações gera um gráfico no qual é possível comparar a temperatura do gusa liquido em cada situação considerada no decorrer do tempo. Além disso, avaliando separadamente cada um dos meios de transferência de calor, pode-se obter um gráfico mostrando a contribuição de cada meio para a perda térmica total do gusa líquido. Será avaliado por meio dessas equações como é a perda térmica de 80 toneladas de gusa líquido, variando de $1550^{\circ} \mathrm{C}$ até $1400^{\circ} \mathrm{C}$, em uma panela bem encharcada. Os gráficos gerados como respostas serão mostrados mais adiante.

\section{RESULTADOS E DISCUSSÃO}

\subsection{Modelo de Logística de Movimentação}

Para todos os cenários propostos, foram feitas inicialmente várias simulações, procurando-se obter como respostas o número mínimo de panelas que deveriam ser utilizadas no circuito simulado. Além disso, devem-se repetir as simulações também para se encontrar qual seria a programação ideal do forno elétrico, pois esta é um dado de entrada da simulação e varia para cada uma das corridas que usam, ou não, gusa líquido proveniente do AF. O fato da programação do FEA ser um dado de entrada na forma de horários das corridas possibilita ao usuário simular um intervalo de parada entre sequências de corridas do FEA.

Para todos os cenários, o número mínimo de panelas que deveriam ser utilizadas no circuito foi de duas panelas.

\subsubsection{Alto-Forno com produtividade de $1,6 \mathrm{t} / \mathrm{dia} / \mathrm{m}^{3}$}

Trabalhando com uma produtividade 1,6 t/dia/m3, e mantendo-se o forno aberto por 3 horas e fechado por 1 hora, obtém-se um número de seis corridas do alto-forno por dia de operação. Operando nessas condições, cada corrida do alto-forno produziria, aproximadamente, 93 toneladas. Nesse cenário optou-se por utilizar apenas uma panela em cada corrida do alto-forno, acumulando as 93 toneladas de gusa líquido para ser basculado no FEA.

Uma parte do gráfico de Gantt gerado como resposta à simulação desse cenário está apresentada na Figura 5 abaixo:

* Contribuição técnica ao $44^{\circ}$ Seminário de Redução de Minério de Ferro e Matérias-primas, 15오 Simpósio Brasileiro de Minério de Ferro e 2ํ Simpósio Brasileiro de Aglomeração de Minério de Ferro, 15 a 18 de setembro de 2014, Belo Horizonte, MG, Brasil. 


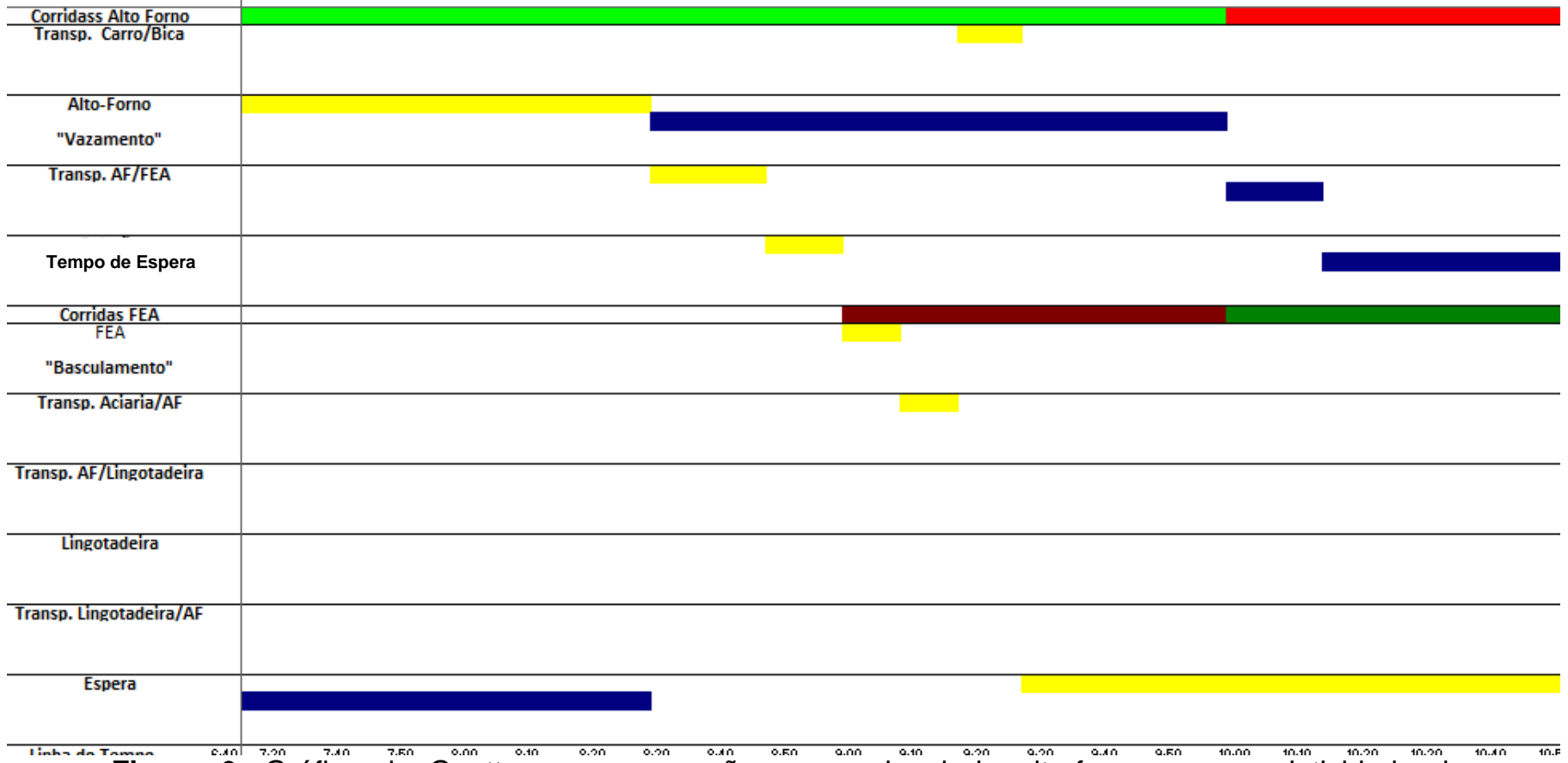

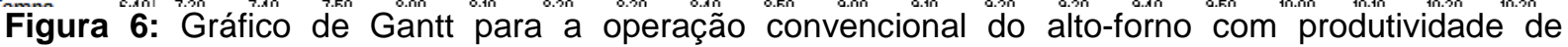
$2,4 \mathrm{t} / \mathrm{m}^{3}$.dia.

Mais uma vez, a análise do gráfico completo revela que deve-se utilizar pelo menos duas panelas no circuito. Novamente, nenhuma panela teve que ser enviada para a lingotadeira, para se evitar que o gusa se solidificasse em seu interior. Além disso, conclui-se que a panela 1 (em amarelo) está disponível entre 1:00 e 1:30 para manutenções ou aquecimento entre duas utilizações consecutivas no circuito, enquanto a panela 2 (azul) apresenta um intervalo de 0:30 a 1:20. Novamente, a análise do gráfico possibilita ao usuário identificar quais foram as corridas do FEA que utilizaram gusa-líquido proveniente do AF.

Os indicadores calculados mostram que uma a cada duas corridas do forno elétrico utilizaram gusa-líquido proveniente do alto-forno, totalizando 13 das 24 simuladas. A taxa de utilização da ponte rolante foi de $16,9 \%$, a panela 1 passa cerca de $58 \%$ do tempo total simulado com gusa líquido em seu interior enquanto a panela 2 passa $59 \%$.

\subsection{Análise das Perdas Térmicas}

A Figura 7 mostra o gráfico gerado pela integração numérica das equações 1 e 2 , para avaliação das perdas térmicas do gusa dentro da panela. Além desses valores, foram incluídos dados reais, medidos em um experimento no qual a panela estava sem a tampa, mas, após o recebimento do gusa líquido, foi adicionada com uma cobertura de palha de arroz.

\footnotetext{
* Contribuição técnica ao 44ํ Seminário de Redução de Minério de Ferro e Matérias-primas, 15ํ Simpósio Brasileiro de Minério de Ferro e $2^{\circ}$ Simpósio Brasileiro de Aglomeração de Minério de Ferro, 15 a 18 de setembro de 2014, Belo Horizonte, MG, Brasil.
} 


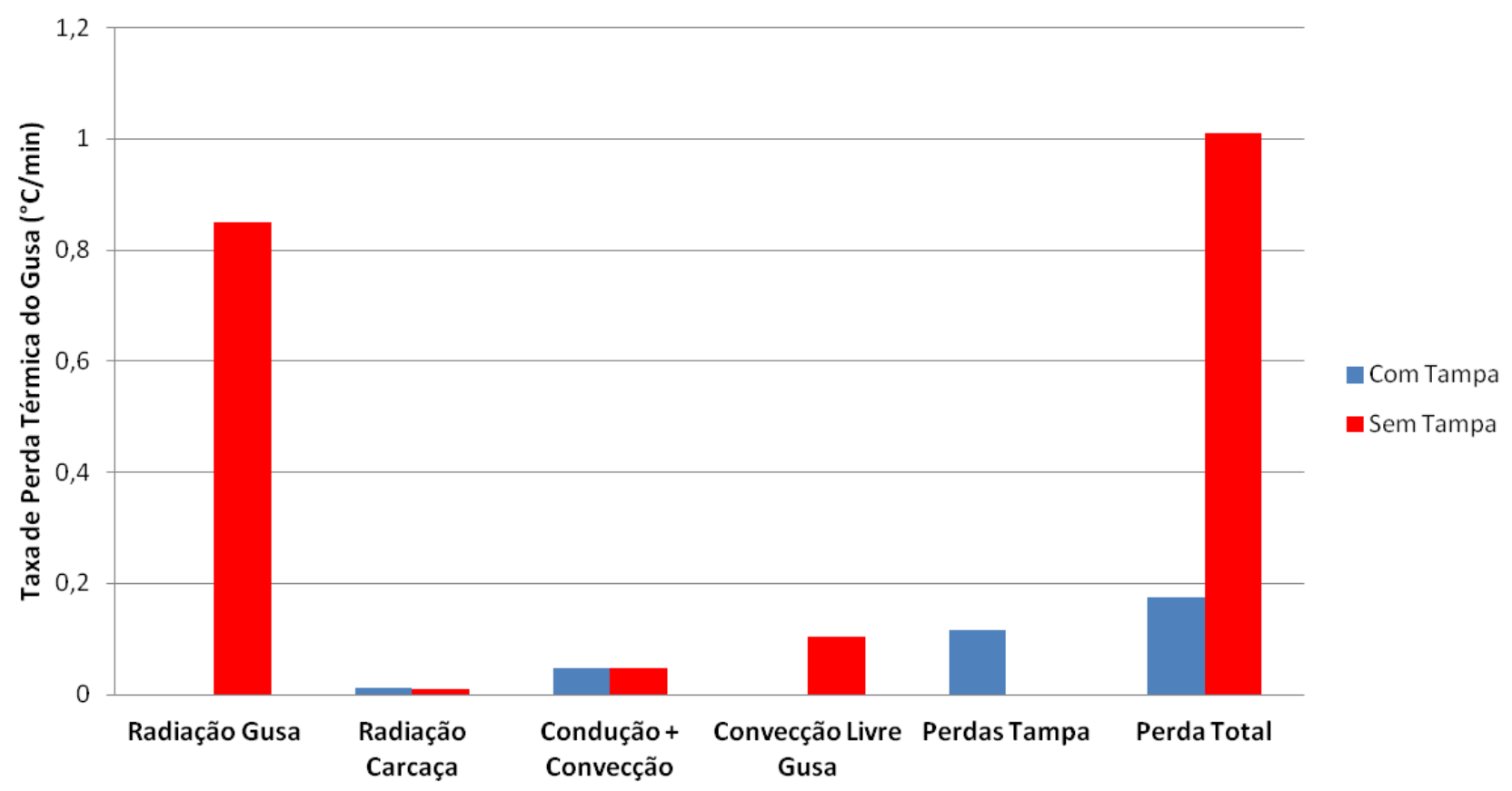

Figura 8. Contribuição de cada meio de transferência de calor para a perda térmica total.

A análise desse gráfico mostra que mais de $60 \%$ da perda térmica total da panela destampada se deve à radiação da superfície de gusa, que se encontra exposta para 0 ar. Isso reforça a necessidade de utilizar uma cobertura ou a tampa da panela para se evitar essa grande perda.

\section{CONCLUSÃO}

De acordo com as simulações propostas chegou-se às seguintes conclusões:

i. para todos os cenários simulados, um mínimo de duas panelas é necessário para atender às demandas do alto-forno;

ii. para uma produtividade de $1,6 \mathrm{t} / \mathrm{dia} / \mathrm{m}^{3}$, em um cenário de 24 corridas do FEA, 7 corridas foram atendidas com cerca de 93 toneladas de gusalíquido proveniente do AF. Em aproximadamente $50 \%$ do tempo total, as panelas estariam com gusa-líquido dentro;

iii. para uma produtividade de $2,4 \mathrm{t} / \mathrm{dia} / \mathrm{m}^{3}$, em um cenário de 24 corridas do FEA, uma a cada duas corridas foram atendidas com cerca de 70 toneladas de gusa-líquido proveniente do AF. Em aproximadamente $58 \%$ do tempo, as panelas estariam com gusa-líquido dentro delas.

Foi feita também a análise das perdas térmicas do gusa líquido em uma panela com a superfície exposta e tampada. Foi possível comparar as perdas térmicas do gusa em uma panela exposta, com cobertura de palha de arroz e coberta com a tampa e a análise mostrou que mais de $60 \%$ da perda térmica total da panela destampada se deve à radiação da superfície de gusa, que se encontra exposta para o ar. Concluiuse que é necessário utilizar uma cobertura ou a tampa da panela para se evitar essa grande perda.

\footnotetext{
* Contribuição técnica ao 44ํ Seminário de Redução de Minério de Ferro e Matérias-primas, 15ํ Simpósio Brasileiro de Minério de Ferro e $2^{\circ}$ Simpósio Brasileiro de Aglomeração de Minério de Ferro, 15 a 18 de setembro de 2014, Belo Horizonte, MG, Brasil.
} 


\section{Agradecimentos}

Agradecemos aos amigos da equipe de estagiários da RSConsultants, em especial Dieggo Armando Thomaz, pelo incentivo, apoio e amizade em todas as horas de trabalho.

Aos companheiros da área de alto-forno e aciaria da VSB pelas experiências compartilhadas e por valorizarem e reconhecerem 0 esforço empregado no desenvolvimento desse projeto.

\section{BIBLIOGRAFIA}

1 Incropera FP, DeWitt DP, Bergman TL, Lavine AS. Fundamentos de Transferência de Calor e Massa. Rio de Janeiro. LTC-Livros Técnicos e Científicos. 2008. 